\title{
The Relationship of Plasma Adiponectin with Liver Fibrosis in Morbid Obesity
}

\author{
Teoman Dogru • Nuri Karadurmus • Guldem Kilciler • \\ Serkan Tapan $\cdot$ Cemal Nuri Ercin
}

Published online: 10 July 2010

(C) Springer Science+Business Media, LLC 2010

To the Editor:

Nazal et al. reported some interesting data regarding a relation between plasma adiponectin concentrations and liver histology in morbidly obese patients [1]. Although most clinicians believe that an association is already present [2], the study is important because it provides scientific information on this clinically relevant condition.

However, we think that some points should be discussed. Firstly, as stated in the text and shown in Table 1, there are significant differences regarding the body mass index, highdensity lipoprotein cholesterol and triglyceride levels, and also the proportions of subjects with hypertension and diabetes mellitus (DM). It is well known that all these parameters affect circulating adiponectin concentrations [3]. Secondly, apart from DM, no information about the glucose tolerance of other subjects can be seen in the text. We know from previous studies that hypoadiponectinemia occurs not only in diabetes but also in people with impaired glucose tolerance (IGT) [4], which is a condition with insulin resistance as well. Obesity is a strong risk factor for the development of DM and also IGT. In light of these clear data, we think that some of the study participants may still have overt glucose dysregulation or DM without implementation of the glucose tolerance test. This issue is important because non-alcoholic fatty liver disease (NAFLD) is associated with prediabetes and circulating

T. Dogru $\cdot$ G. Kilciler $\cdot$ C. N. Ercin Department of Gastroenterology, Gulhane School of Medicine Etlik, Ankara, Turkey

\section{N. Karadurmus $(\bowtie)$}

Department of Internal Medicine,

Gulhane School of Medicine Etlik, Ankara, Turkey

e-mail: drnkaradurmus@yahoo.com

\section{S. Tapan}

Department of Biochemistry,

Gulhane School of Medicine Etlik,

Ankara, Turkey adiponectin and insulin concentrations are altered in subjects with disordered glucose metabolism [5]. Lastly, no information about the drug use of the subjects could be seen in the text. We know that adiponectin blood levels and measures of insulin sensitivity may be affected from the medications started for the metabolic problems mentioned above [6, 7].

Finally, we would like to ask the authors whether they can present some additional data by categorizing their patients with metabolic syndrome and NAFLD according to metabolic confounders such as DM, IGT, blood pressure, lipid profile, and medication. This would certainly provide the readers clearer information about the association between adiponectin and liver histology in patients with morbid obesity.

Conflict of interest disclosure We have no conflict of interest.

\section{References}

1. Nazal L, Riquelme A, Solis N, et al. Hypoadiponectinemia and its association with liver fibrosis in morbidly obese patients. Obes Surg. 2010; doi:10.1007/s11695-009-0051-0.

2. Huang HL, Lin WY, Lee LT, et al. Metabolic syndrome is related to nonalcoholic steatohepatitis in severely obese subjects. Obes Surg. 2007; 17:1457-63.

3. Gulcelik NE, Usman A, Gurlek A. Role of adipocytokines in predicting the development of diabetes and its late complications. Endocrine. 2009; Sep 25. doi:10.1007/s12020-009-9234-7.

4. Otsuka F, Sugiyama S, Kojima S, et al. Hypoadiponectinemia is associated with impaired glucose tolerance and coronary artery disease in non-diabetic men. Circ J. 2007;71:1703-9.

5. Yun JW, Cho YK, Park JH, et al. Abnormal glucose tolerance in young male patients with nonalcoholic fatty liver disease. Liver Int. 2009;29(4):525-9.

6. Yilmaz MI, Sonmez A, Caglar K, et al. Effect of antihypertensive agents on plasma adiponectin levels in hypertensive patients with metabolic syndrome. Nephrology (Carlton). 2007;12:147-53.

7. Lee JM, Kim JH, Son H, et al. Valsartan increases circulating adiponectin levels without changing HOMA-IR in patients with type 2 diabetes mellitus and hypertension. J Int Med Res. 2010;38:234-41. 